\title{
CHEMBOND3D e-Module Effectiveness in Enhancing Students' Knowledge of Chemical Bonding Concept and Visual-spatial Skills
}

\author{
Vui Ket Kuit ${ }^{1}$, Kamisah Osman 2*, \\ ${ }^{1}$ Faculty of Education National University of Malaysia 43600 Bangi Selangor, MALAYSIA \\ 2 The National University of Malaysia, MALAYSIA \\ * Corresponding author: kamisah@ukm.edu.my
}

Received: 17 Jul. 2021 Accepted: 11 Sep. 2021

Citation: Kuit, V. K., \& Osman, K. (2021). CHEMBOND3D e-Module Effectiveness in Enhancing Students' Knowledge of Chemical Bonding Concept and Visual-spatial Skills. European Journal of Science and Mathematics Education, 9(4), 252-264. https://doi.org/10.30935/scimath/11263

\begin{abstract}
:
Today's educational challenges necessitate the creative use of digital technology to adapt an effective pedagogical approach in chemistry teaching. While various visualization tools have been developed to improve visual-spatial skills, previous studies on digital technology interventions provide limited findings and show moderate effects on students' learning. Moreover, students still have misconceptions even after using three-dimensional models physically or virtually while learning chemical bonding. Therefore, this study investigates the effectiveness of the CHEMBOND3D e-module that integrates the web-based visualization tool, Molview, on the chemical bonding concept knowledge and visual-spatial skills between treatment groups and control groups. A pretest-posttest non-equivalent control group with a quasiexperimental quantitative design is used in the research. Pilot studies were conducted to verify the validity and reliability of the CHEMBOND3D Chemical Bonding Knowledge Test and Revised Purdue Visualization Test of Rotations. A total of 112 pre-university students from 10 schools in Sabah were selected based on the sampling method. The findings showed significant improvement in the chemical bonding concept knowledge and visual-spatial skills for treatment group students using CHEMBOND3D e-module compared to control group students using conventional methods. This provides new evidence of the potential of web-based application in learning microscopic chemistry concept in chemical bonding. These findings can facilitate further studies of other digital visualization tools such as virtual reality and augmented reality in support of learning complex chemistry concepts in reaction mechanisms and chemical equilibrium. Keywords: visualization, module, visual-spatial skills, knowledge, chemical bonding
\end{abstract}

\section{INTRODUCTION}

Chemistry is a discipline in the field of science that investigates the macroscopic and microscopic matter, production and application of materials, and interactions between substances. Johari and Yusof (2002) found students used their five senses to describe something invisible to their naked eyes in understanding the complexity of abstract chemistry concepts. Consequently, students' minds and thoughts can be manipulated to reason logically, visualize and imagine to understand the concepts learnt.

In understanding a chemistry concept, students should be able to integrate conceptual knowledge with visual-spatial skills to produce, maintain and manipulate an abstract visual image (Lohman, 1979). This skill is crucial for students to distinguish the mental image from real images through physical molecular models or representations on computer displays. Although educators are aware of the importance of these skills, various studies show students have difficulty to visualize the shape and structure of molecules in chemical bonding because this capability requires high visual-spatial skills (Mohamed- 
Salah \& Alain, 2016; Pérez et al., 2017). Studies by Pérez et al. (2017) and Ibrahim, Othman and Talib (2015) found that students tend to flatten the molecule representation in wedge-dash structure into Fischer projection regardless of the difference in the spatial arrangement between the two forms of representation (Olimpo et al., 2015).

Since teaching methods using two-dimensional images of molecules were found to be less successful in enhancing the conceptual knowledge and students' visual-spatial skills, educators have proposed interventions using 3D molecules. According to Bugaje (2013), interventions using three-dimensional model representation either in physical or virtual form have improved student performance (Okoye, 2016; Ulrich, 1991). As a result, various interventions incorporating digital technologies have been applied in teaching stereochemistry, hybridization, chemical bonding, and formation of polymer (Abraham et al., 2010; McCollum et al., 2014; Nechypurenko et al., 2018; Rayan \& Rayan, 2017; OliverHoyo \& Babilonia-Rosa, 2017). Their effectiveness depends on the creativity of educators and student aptness (Okorie et al., 2019). In chemistry teaching, teachers tend to use more concrete 3D physical or virtual models (Koyanagi et al., 2005). According to Hong and Woo (2006), the three-dimensional model representation presented virtually on a computer screen is easier to visualize than models in physical form. The findings were also supported by the study of Nechypurenko et al. (2018), which showed that students were able to visualize atomic structures, molecules and crystals better when taught chemical bonding using three-dimensional virtual models.

As a result, various visualization tools have been developed to create virtual molecular structures. A survey by Craig et al. (2013) of 32 visualization tools found Pymol and Jmol were the most popular software for virtual three-dimensional molecular visualization because they were easy to use. Furthermore, these applications that have diverse, interesting features could be applied in laptops and smartphones as well (Craig et al., 2013). The dawn of the Industrial Revolution 4.0 (IR4.0) led to a technological boom. Fatemah et al. (2020) as well as Brown et al. (2020) have developed several interactive applications that integrate virtual reality technology, including StereoChem (Narasimha Swamy et al., 2018) and augmented reality, MoleculAR. Both applications provide a new experience for users, especially school children. However, they can only display images of molecular models through markers' images infused in text or display images in textbooks (Fatemah et al., 2020).

Although several studies have been carried out on teaching methods that effectively enhance the conceptual knowledge and spatial-visual skills among students, a meta-analysis by Sung et al. (2016) on the effects of digital technology interventions still show moderate impact on students' learning achievements. Thus, this study will integrate Molview for students to visualize the form of molecules in three-dimensional settings while learning chemical bonding. Moreover, this web-based visualization tool is free and is easily accessible using a laptop or smartphone at any time without having to download. It fits well as the main medium in the implementation of the CHEMBOND3D e-module that promotes self-directed independent learning by students.

\section{LITERATURE REVIEW}

Submicroscopic chemistry topics are both visually and conceptually challenging issues in the world of education. The nature of atoms and molecules during physical and chemical changes is not easily illustrated as it requires a good understanding of three levels of representation and the ability to learn the symbolic representation in chemistry. According to Johnstone (1993), students often use symbolic representation without understanding the chemistry concepts thematically associated with these representations due to the high cognitive burden among students (Kozma, 2003). A study by Yaseen (2018) on trainee primary school science teachers revealed that most of them could not describe macroscopic and symbolic representation and understand the chemical concept related to the nature of the matter because of the static representation of the molecules. Therefore, the effective use of teaching materials can lead to a transition between these levels and contribute to high-level thinking that 
enhances chemistry learning (Brown et al., 2020; Fatemah et al., 2020; Mohamed-Salah \& Alain, 2016: Swamy et al., 2018).

The vast application of visualization tools in science education enables learning science concepts involving dynamic chemical aspects in line with Constructivism Theory. They can help students shift between submicroscopic chemical levels (molecular world) and macroscopic chemical levels (world to be observed) (Yaseen, 2018). Visualization tools have been used to describe the form of molecules (submicroscopic levels) and the properties of chemical molecules (macroscopic levels), and help students understand the concept of transition between levels (macroscopic, submicroscopic and symbolic). Studies have shown that displaying the form of molecules in three-dimensional settings helps students to develop their conceptual understanding of specific topics related to chemical bonding. It aids in their understanding of atomic orbitals (S.C. Chen, 2015), chemical bonding (Fatemah et al., 2020; Karacop \& Doymus, 2013; Ozdemir, 2010), general chemistry (Al-Balushi et al., 2017), electrochemistry (Yang et al., 2003), dissolution in water molecules (Falvo \& Suits, 2009), dynamic fluid equilibrium (Hinze et al., 2013), molecular models (Brown et al., 2020; Merchant, 2012; Mohamed-Salah \& Alain, 2016; Ozdemir, 2010; Schönborn, 2011), and organic chemistry (Stieff, 2014; Swamy et al., 2018).

In line with the development of educational technology in the IR4.0 age and the blooming of virtual reality and Internet of Things (IoT), teaching methods transformed from conventional methods to the use of electronic-based learning, i.e. e-learning (Rosnani, 2018). This has led to the creation of many computer-based visualization tools such as StereoChem (Swamy et al., 2018), 3D printing models (Penny et al., 2017) and Jmol (Fatemah et al., 2020). They can generally be categorized into model building tools, multimedia learning tools and learning environments. Although each of these interventions has a specific function, they have been developed based on constructivism and social learning theories whereby students build their knowledge based on their experience through observation and learning interaction with their peers (Bandura, 1977; Piaget, 1954).

Although Udo and Etiubon (2011) reported that the construction of models and representations is a commonly known method often practised when teaching chemistry, the application of online molecular model visualization tools is inadequate, especially at the pre-university level (Gabel, 1993). There is still a lack of relevant literature on research that integrates inquiry-based teaching approaches based on the $5 \mathrm{E}$ teaching model even after nearly 10 years of integration of technology to transform the dynamics of education (Louca \& Zacharia, 2012). Thus, there is an urgency to develop such innovative teaching approaches which have several advantages over traditional face-to-face learning (Smith \& Hardaker, 2000).

As illustrated in Figure 1, the development of the CHEMBOND3D e-module suggested in this study is based on Constructivism Theory (Piaget, 1954), Social Learning Theory (Bandura, 1977) and Cognitive Theory of Multimedia Learning (Mayer, 2009). It is envisaged that this module will enable students to develop their knowledge of chemical bonding by synthesizing new experiences through threedimensional molecular visualization using Molview via hands-on activities (Brooks \& Brooks, 1993). In addition, this module emphasizes the interaction between the students on the virtual models with the surrounding to achieve the desired learning outcomes. The integration of multimedia as a cognitive tool in this module helps students to minimize short-term memory loads while learning abstract chemical bonding concepts, choosing information, building relationships and mental models. Thus, it promotes deep learning while enhancing students' chemical bonding concept knowledge and visual-spatial skills (Mayer et al., 2018). 


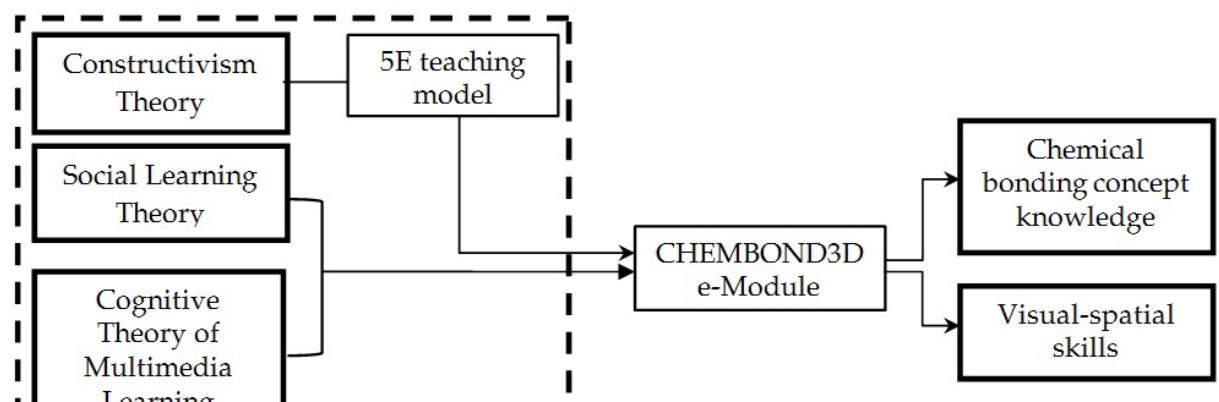

Figure 1. Research conceptual framework

This research was conducted throughout the synchronous lessons incorporated in CHEMBOND3D emodule in teaching chemical bonding concepts using Molview. It was to investigate if there was a significant difference in the chemical bonding concepts knowledge and visual-spatial skills between treatment and control groups of students before and after interventions were carried out.

\section{Research Objectives and Null Hypothesis}

In line with the problem statements discussed, the objective of this study was to determine the effectiveness of the CHEMBond3D e-module in enhancing students' knowledge in chemical bonding concept and visual-spatial skills. Specifically, the hypotheses are:

Ho1: There is no significant difference in the knowledge in chemical bonding concept between treatment groups using the CHEMBOND3D e-module and control groups using conventional methods.

$\mathrm{H}_{\circ} 2$ : There is no significant difference in visual-spatial skills between treatment groups using the CHEMBOND3D e-module and control groups using conventional methods.

\section{METHODOLOGY}

\section{Research Design}

A pretest-posttest non-equivalent control group with a quasi-experimental quantitative design was used in the research. Prior to the lesson, pretest of the CHEMBOND3D Chemical Bonding Knowledge Test and Revised Purdue Visualization Test of Rotations Test were administered to both the control and treatment groups in the first week. The two groups then had four weeks of formal synchronous lessons, learning chemical bonding concept via Google Meet. For the treatment group, teacher integrated CHEMBOND3D e-module with three-dimensional molecules were displayed via Molview. The students in the control group learnt similar topics in the conventional method, using textbooks, teachers' handouts and PowerPoint presentations that displayed two-dimensional molecules. In the fourth and final week, students from both treatment and control groups were administered the posttest of the CHEMBOND3D Chemical Bonding Knowledge Test and PSVT:R. Table 1 shows a summary of the quasi-experimental design approach used in this study.

Table 1. Research design of quasi-experimental

\begin{tabular}{lccc}
\hline Type of group & Pretest & Treatment & Posttest \\
\hline Control & $\mathrm{O}_{1}$ & $\mathrm{X}_{1}$ & $\mathrm{O}_{2}$ \\
Treatment & $\mathrm{O}_{1}$ & $\mathrm{X}_{2}$ & $\mathrm{O}_{2}$ \\
\hline
\end{tabular}

Indicators:

$\mathrm{X}_{1}$ : Control group (Chemical bonding concept learnt without using CHEMBOND3D e-module).

$\mathrm{X}_{2}$ : Treatment group (Chemical bonding concept learnt using CHEMBOND3D e-module).

O1: Pre-test

$\mathrm{O}_{2}$ : Post-test 


\section{Participants}

The sample size was determined in proportion to the population size. Hence, a total of 10 secondary schools were identified from a total of 29 secondary schools that offering Chemistry subject in their preuniversity studies. The remaining 19 schools are excluded in this research due to the location of the school in the rural areas, unreliable internet connection, and taught by novice teacher with less than 10 years experience. Students were selected using purposive sampling using simple randomization to prevent selection bias thus each of the student has an equal chance of being assigned to treatment or control group (Ferreira \& Patino, 2016). This is because students in Malaysian secondary schools are placed in different classes and streams. Other criteria such as access to Internet facilities and gadget ownership were also taken into account since the CHEMBOND3D e-module would be implemented entirely online. Only teachers with a minimum of 10 years of teaching experience were selected to avoid unnecessary variation in teaching method between pre-service and experienced teachers. Teachers involved in this research recognized as competent or above-average classroom managers, and were recommended by their school leaders as experts in the teaching profession (Palmer et al., 2005). These teachers were also required to obtain the permission and support of the school administators. Once samples have been identified, permission was obtained from the principals of the schools involved. Subsequently, formal consent and ethical clearance were obtained from the Education Planning and Research Division, Ministry of Education, and the Sabah State Education Department before the research was conducted with the teachers and students.

A total of 112 pre-university students between the ages of 18 and 19 from 10 urban secondary schools in Sabah were selected for this research (Table 2). However, only 79 students were shortlisted for the descriptive and inferential analysis due to incomplete instruments, not answering either pretest or posttest.

Table 2. The number of students from each school involved in this research

\begin{tabular}{lcccc}
\hline Name of school & Number of students & Total & Group & Approach \\
\hline School A & 16 & 62 & Control & Using conventional teaching \\
School B & 2 & & & methods such as textbooks and \\
School C & 13 & & \\
School D & 4 & & \\
School E & 3 & & \\
School F & 17 & & \\
School G & 7 & 50 & Treatment & Teaching methods using \\
School H & 6 & & CHEMBOND3D e-module \\
School I & 17 & & \\
School J & 27 & & & \\
\hline
\end{tabular}

Several measures have taken to avoid issues that may affect the internal and external validity of the research. These include internal threats of maturation (age, experience and level of knowledge), history (control groups' background and school activities related to chemistry learning that could affect the learning variables), testing (sequence of items manipulated during posttest), instrumentation (content and face validity of instruments from experts), participant selection (homogeneity between control and treatment groups), mortality (the participation of consistent study participants throughout the study) and social interaction (participants of control groups and treatments selected from different schools). For external validity, the concerns include interaction between procedures and treatments. (Participants were selected from urban secondary schools based on the school timetable to avoid reactive effects. These participants were not informed about other groups of students who participated in the research and the interaction between the selection of participants with the interventions). The aim and hypothesis of this research were not informed in detail to the participants. 


\section{Instruments}

The study used two instruments, the CHEMBOND3D Chemical Bonding Knowledge Test and the Revised Purdue Visualization Test of Rotations (PSVT: R).

\section{CHEMBOND3D Chemical Bonding Knowledge Test}

This instrument is developed to study the effectiveness of the CHEMBOND3D module on students' knowledge of the chemical bonding concept compared to conventional teaching methods. Table 3 shows subtopics covered in the chemical bonding concept, the type and number of items and examples. All of these items will measure the students' level of knowledge, understanding and application of the chemical bonding concept. This instrument was validated by a senior lecturer in chemistry and two preuniversity chemistry expert teachers with more than 10 years of experience. The reliability of the CHEMBOND3D Chemical Bonding Knowledge Test showed a strong correlation $(r=+0.96, p<0.001)$ between pretest and posttest. This was done through a pilot study involving 37 respondents.

Table 3. Subtopics in the chemical bonding concept, the type and number of items and the examples of items in the CHEMBOND3D Chemical Bonding Knowledge Test

\begin{tabular}{|c|c|c|c|}
\hline Subtopics & Types & $\begin{array}{l}\text { Number } \\
\text { of items }\end{array}$ & Examples \\
\hline $\begin{array}{l}\text { Lewis structure, ionic and covalent } \\
\text { bonding }\end{array}$ & \multirow{5}{*}{$\begin{array}{l}\text { Multiple- } \\
\text { choice } \\
\text { questions }\end{array}$} & \multirow[t]{5}{*}{10} & $\begin{array}{l}\text { Which statement about the Lewis structure of } \mathrm{CO}_{3}^{2-} \text { ad } \mathrm{NO}_{3}^{-} \\
\text {ions is true? }\end{array}$ \\
\hline Polar and non-polar molecule & & & A. Both ions are trigonal-planar in shape. \\
\hline Shapes of molecules and ions and their & & & B. Both ions have a formal charge on the central atom. \\
\hline \multirow[t]{2}{*}{ bond angles } & & & C. Both ions form two double bonds and one single bond. \\
\hline & & & $\begin{array}{l}\text { D. Both ions have central atoms with one pair of unpaired } \\
\text { electrons. }\end{array}$ \\
\hline Lewis structure & \multirow{2}{*}{$\begin{array}{l}\text { Structured } \\
\text { question }\end{array}$} & \multirow[t]{2}{*}{2} & Draw the Lewis structures for $\mathrm{NH}_{4}^{+}$and $\mathrm{NO}_{3}{ }^{-}$ions and \\
\hline Ionic compounds and covalent compounds & & & predict their shapes. [4 marks] \\
\hline Lewis structure and shape of ions & \multirow{4}{*}{$\begin{array}{l}\text { Essay } \\
\text { question }\end{array}$} & \multirow[t]{4}{*}{1} & An ammonia molecule accepts one hydrogen ion to form an \\
\hline Dative covalent bond & & & ammonium ion or loses one hydrogen ion to form an amide \\
\hline Polar and non-polar molecule & & & ion. Draw the Lewis structures of ammonium and amide \\
\hline & & & ions. Compare the shapes of the two ions. [8 marks] \\
\hline
\end{tabular}

\section{Revised Purdue Visualization Test of Rotations (PSVT:R)}

This instrument consists of 30 items. It tests the students' visual-spatial skills by requiring them to identify the form of the three-dimensional object after rotation occurs. Figure 2 shows the examples of items tested in this PSVT:R test.

The instrument was modified from the original version developed by Bodner and Guay (1997). It showed a high Cronbach alpha value reading of 0.84 compared to the original version and was modified to suit students aged 13 and above (Yoon, 2001). Based on previous studies related to visual-spatial thinking, Wu and Shah (2004) found that this instrument is suitable to gauge visual-spatial skills. In addition, this instrument was used in several research to measure the effectiveness of interventions of teaching methods in improving visual-spatial skills, including the integration of digital technology equipment in subjects that fall under science, technology, engineering and mathematics (STEM) disciplines (Bodner \& McMillen, 1986; Brown et al., 2020; Moore, 2017; Murray, 2016; Safadel \& White, 2020; Which et al., 2003). 

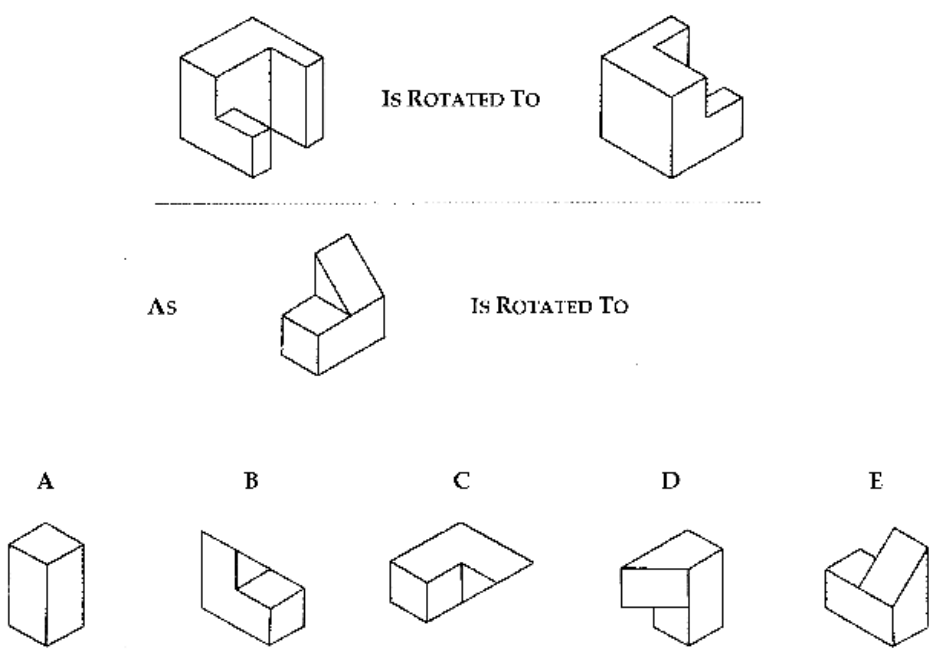

Figure 2. Examples of items that test student visual-spatial skills in PSVT: R

\section{CHEMBOND3D e-Module}

The CHEMBOND3D e-module is an electronic module developed based on the ADDIE model that integrates Molview, a web-based application, to draw and visualize molecules in three dimensions (Figure 3). This module accommodates two lesson plans that will focus on two important concepts in chemical bonding, which are Lewis structure and Valence Shell Electron Pair Repulsion (VSEPR) to determine the shape of ions or molecules and bond angle. This can be carried out in four teaching sessions in accordance with the proposed teaching time for these subtopics stipulated by the Malaysian Examinations Council. The teaching session using this e-module will be conducted entirely online using the Google Meet application while integrating the 5E teaching model incorporating inquiry-based approaches (Bybee et al., 2006). This module was evaluated by five experts to ensure that it has included all contents to be tested and were in line with the aim of the research. A pilot study was done to assess ease of use, learnability and user satisfaction of the module. The pilot study was to ensure reliability and good usability of the CHEMBOND3D e-module before it was introduced to its target audience.
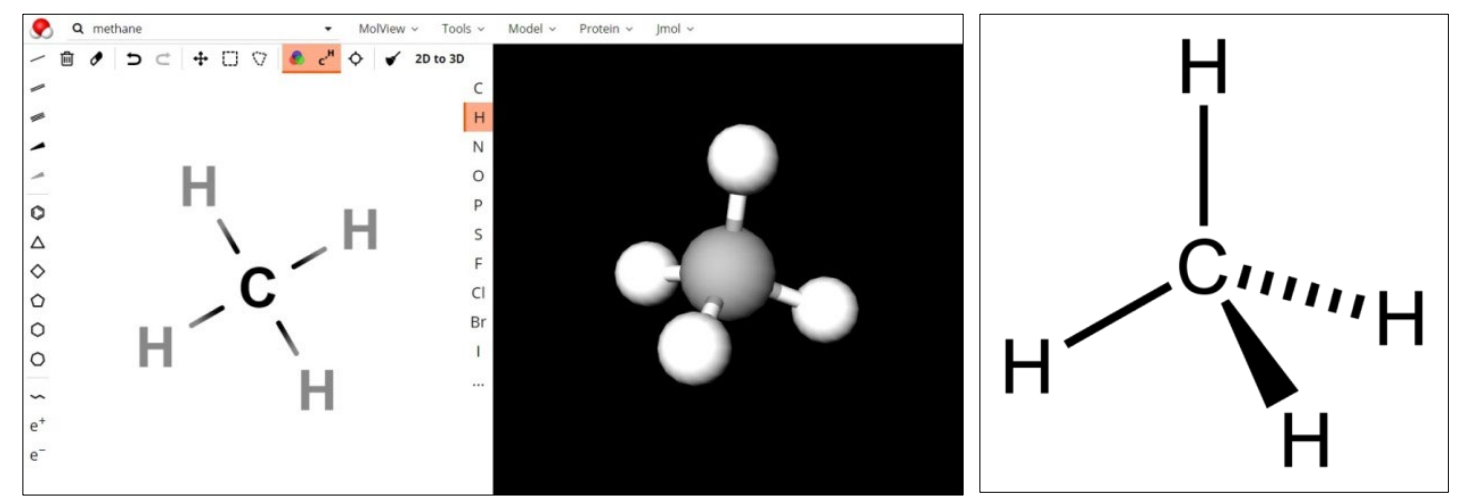

Figure 3. Three-dimensional visualization for methane molecules that can be pan, rotate and zoom in Molview (left) in compare to two-dimensional visualization for the over-simplified model of the similar molecule in textbook (right)

\section{Intervention Strategy}

Prior to the intervention, pretest of the CHEMBOND3D Chemical Bonding Knowledge Test and PSVT:R Tests was administered to the treatment group $(n=50)$ and control group $(n=62)$ in the first week. Interventions were then introduced by teachers. They taught Chemical Bond topics to treatment groups using the CHEMBOND3D e-module through Google Meet where three-dimensional molecules were 
displayed via Molview. In contrast, students in the control group learnt similar topics in the conventional method, using textbooks, teachers' handouts and PowerPoint presentations that displayed twodimensional molecules. In the fourth week, students from both treatment and control groups were administered with posttest of the CHEMBOND3D Chemical Bonding Knowledge Test and PSVT:R. Answer scripts of the pre- and post-tests were evaluated by two experienced pre-university chemistry teachers.

\section{Data Analysis}

The research data was analyzed using Statistical Package for Social Science (SPSS) software version 26, followed by hypothesis testing using independent sample t-tests.

\section{RESULTS}

As indicated in Table 4, the pretest results showed the knowledge of chemical bonding concept and visual-spatial skills were homogenous among students in both the control and treatment groups.

Table 4. Average score, standard deviation and t-test for the pre-knowledge test of the chemical bonding concept knowledge and visual-spatial skills for control group and treatment group

\begin{tabular}{lcccccc}
\hline Dependent variable & Group & $\mathrm{N}$ & $\mathrm{M}$ & $\mathrm{SD}$ & $\mathrm{t}$ & \multicolumn{1}{c}{$\mathrm{p}$} \\
\hline Chemical bonding concept knowledge & Control & 49 & 16.69 & 5.709 & 6.175 & \\
& Treatment & 30 & 16.93 & 6.181 & \\
\hline Visual-spatial skills & Control & 49 & 20.20 & 5.881 & 1.111 \\
& Treatment & 30 & 18.70 & 5.778 & & 0.270 \\
\hline
\end{tabular}

Independent sample t-test at a significant level $\alpha \mathrm{p}=0.05$ found no significant difference in chemical bonding concept knowledge between control and treatment groups $(\mathrm{t}(78)=-0.175, \mathrm{p}=0.861)$. Levene test results for variance homogeneity indicates that the variance population is homogeneous with value $\mathrm{F}=$ 0.0001 and $p>0.05$. Independent sample t-test on visual-spatial skills also showed no significant difference between control and treatment groups $(\mathrm{t}(78)=1.111, \mathrm{p}=0.270)$. Levene statistical pre-test for visual-spatial skills also showed an insignificant value on $\alpha=0.05$ ( $F=0.018, \mathrm{p}>0.05)$. In conclusion, it it is deduced that the variance of data distribution is homogeneously observed (Martin \& Bridgmon, 2012).

Subsequently, data analysis using independent sample t-test for post-test chemical bond concept knowledge for the control and treatment groups shows significant differences in chemical bond concept knowledge $(t=-2.242, d f=77, p=0.028, p<0.05)$ which is a mean increase of 3.57 with $95 \%$ confidence and medium effect size, $d=0.52$ (Cohen 1988) for the treatment group after using the CHEMBOND3D emodule through Google Meet where three-dimensional molecules were displayed via Molview (Table $5)$.

Table 5. Average score, standard deviation and t-test for post-test chemical bond concept knowledge for the control and treatment groups

\begin{tabular}{lcccccc}
\hline Dependent variable & Group & $\mathrm{N}$ & $\mathrm{M}$ & $\mathrm{SD}$ & $\mathrm{t}$ & $\mathrm{p}$ \\
\hline Chemical bonding concept knowledge & Control & 49 & 17.53 & 5.767 & -2.242 \\
& Treatment & 30 & 20.50 & 5.625 & 0.028 & \\
\hline
\end{tabular}

As for the visual-spatial skills, data analysis showed a significant improvement in post-test scores for both control and treatment groups $(\mathrm{t}=-2.251, \mathrm{df}=77, \mathrm{p}=0.027, \mathrm{p}<0.05)$, which is a mean increase of 4.20 with $95 \%$ confidence and medium effect size, $d=0.53$ (Cohen 1988) for the treatment group after using the CHEMBOND3D e-module (Table 6). 
Table 6. Average score, standard deviation and t-test for post-test visual-spatial skills for the control and treatment groups

\begin{tabular}{lcccccc}
\hline Dependent variable & Group & $\mathrm{N}$ & $\mathrm{M}$ & $\mathrm{SD}$ & $\mathrm{t}$ & $\mathrm{p}$ \\
\hline Visual-spatial skills & Control & 49 & 20.04 & 5.809 & -2.251 & 0.027 \\
& Treatment & 30 & 22.90 & 4.887 & & \\
\hline
\end{tabular}

\section{DISCUSSION}

The aim of this study is to investigate the effectiveness of the CHEMBOND3D e-module in improving the knowledge of the chemical bonding concept and visual-spatial skills among pre-university students. The results of this research have shown that the CHEMBOND3D e-module has improved the students' knowledge of the chemical bonding concept with the integration of web-based application, Molview. This is evident from the higher mean score differences obtained by students in the treatment group compared with the control group, even though students in the treatment group have significantly lower grade result in chemistry than students in the control group. These findings are significant and in line with those by Karacop and Doymus (2013) and Fatemah, Rasool and Habib (2020), which supported three-dimensional visualization tools as an important intervention in learning chemical bonding, thus enhancing the understanding of advanced chemistry concepts in other subtopics. Despite studies indicating the limitations of spatial-visual stimulus in improving students' achievement (Al-Balushi AlMusawi \& Ambusaidi, 2017; Hoyek et al., 2014; Mohamed-Salah \& Alain, 2016), this research found that this module allowed students to visualize more concrete three-dimensional display of the shapes and bond angle of molecules. Furthermore, it also successfully created active learning that integrated students' inquiry via online learning.

The findings on visual skills in this research corroborate the findings of previous studies on the relationship between academic achievement and visual-spatial skills in subjects other than chemistry (Che et al., 2015; Dayang Suryati \& Mat Rashid, 2015; Rose Khairunisa \& Azlina, 2017). Although the impact of the visual-spatial skills is still disputed by Keehner (2011), and Uttal and Cohen (2012) as a skill that will gradually disappear after students learn, practice, or familiarize themselves with such chemistry topics, the researcher found that the CHEMBOND3D e-module acts as an intermediate medium between visual-spatial skills, specific knowledge domain, and chemistry learning. As such, the integration of this module has helped to reduce cognitive load and had high positive impact on students with lower visual-spatial skills (Wu \& Shah, 2004). In addition, students with higher visual-spatial skills can retain systematically acquired knowledge in long-term memory and can subsequently apply them in complicated problem solving that require higher-order thinking skills.

This research has shown that application of computer-based technologies has a significant positive effect on in knowledge of chemical bonding concept and visual spatial skills. Thus, classroom practice in chemistry teaching and learning needs to place greater emphasis on discourse relating to students' conceptions, the provision of opportunities for students to experience chemistry at the macroscopic, submicroscopic and symbolic levels. Thus, teacher should apply their professional capabilities to lean toward this style of learning by using acceptable concrete representations of the particulate basis of chemical structure and shape. Graphics, tablet games, and videos can be an effective way to make what the students learning chemical bonding more interesting and accessible (Taber, 2005). However, this must be balanced by making shifts between thinking about the symbolic (computer models) and submicroscopic (particle model) levels and provides a suitable platform for future learning.

The application of 3D visualization technology in learning chemistry increases the interest of students and make the learning aid more appealing to them. In addition, it can improve learning and make it more effective. It can also provide better experience by creating a concrete and practical modelling configuration in visualizing molecules to help students who face difficulties in learning (Urso \& Fisher, 2015). Although Lowe (2004), and Korakakis et al. (2009) found that these chemical molecular 
visualization application could cause the "overwhelming" effect among students due to the advantage to observe and re-examine sections of static visuals (3D illustrations) which require high level of conceptive and cognitive processes, the use of information, communication and technology can be a good opportunity to create chemistry learning applications with effective tools to develop new methods and techniques in chemistry educational programmes. Thus, if these programmes improve all students' spatial skills significantly and pass the threshold of spatial skill, this might prepare them to enroll and succeed in STEM disciplines (Gold et al., 2018).

The delivery of verbal and visual description encourages students to actively select relevant information from representation, organize new information and consolidate information into mental models coherently. Thus, building a systematic association between verbal and visual representation. Furthermore, Päßler and Hell (2012) also found that students with better visual-spatial skills tend to further their studies in science-related courses, which are experiencing drastic drops in enrolment in the national education system. Therefore, more research should be carried out to study the correlation between academic achievements and visual-spatial skills in higher education institution. This would eventually lead to more concrete and comprehensive research findings.

\section{CONCLUSION}

Quality chemistry education is crucial to produce human capital that can excel in the field of science. Digital technology offers vast potentials in the online teaching and learning environment. This new reality indeed challenges educators to develop innovative teaching strategies that support online teaching and learning. Hence, the integration of web-based visualization tools enables students to master the chemical bonding concept. This can be used entirely online as a new alternative to help educators address the problem of the absence of face-to-face teaching and empowerment processes compared to the use of concrete physical models. In addition, this teaching method can be extended to teach chemistry in upper secondary school, and also in higher education institutions for science students in matriculation, diploma and bachelor's degree programmes. Since this research focused on students in urban schools, it is suggested that future research should focus on students in rural schools who come from different socio-economic background and may have limited access to Internet facilities. Besides chemical bonding, research can also be carried out on other digital visualization tools such as virtual reality and augmented reality in support of learning complex chemistry concepts such as reaction mechanisms and chemical equilibrium.

Author contributions: All authors were involved in concept, design, collection of data, interpretation, writing, and critically revising the article. All authors approve final version of the article.

Funding: This study is part of Translational Research Grant Scheme study funded by the Ministry of Higher Education (TRGS/1/2018/UKM/01/6/1.).

Declaration of interest: Authors declare no competing interest.

Data availability: Data generated or analysed during this study are available from the authors on request.

\section{REFERENCES}

Abraham, M., Varghese, V., \& Tang, H. (2010). Using molecular representations to aid student understanding of stereochemical concepts. Journal of Chemistry Education, 87(12), 1425-1429. https://doi.org/10.1021/ed100497f

Al-Balushi, S. M., Al-Musawi, A. S., \& Ambusaidi, A. K. (2017). The effectiveness of interacting with scientific animations in chemistry using mobile devices on grade 12 students' spatial ability and scientific reasoning skills. Journal of Science Educational Technology, 26, 70-81. https://doi.org/10.1007/s10956-016-9652-2

Bandura, A. (1977). Social learning theory. Prentice-Hall.

Bodner, G. M., \& Guay, R. B. (1997). The Purdue visualization of rotations test. The Chemical Educator, 4(2), 1-17. https://doi.org/10.1007/s00897970138a

Bodner, G. M., \& McMillen, T. L. B. (1986). Cognitive restructuring as an early stage in problem solving. Journal of Research in Science Teaching, 23, 727-737. https://doi.org/10.1002/tea.3660230807

Brown, C. E., Whaley, B., \& Hyslop, R. M. (2020). Visualizing molecular structures and shapes: A comparison of virtual reality, computer simulation, and traditional modelling. Chemistry Teacher International, 3(1), 1-12. https://doi.org/10.1515/cti2019-0009 
Bugaje, B. O. (2013). Qualitative chemistry education: The Role of the teacher. IOSR Journal of Applied Chemistry (IOSR-JAC), 4(56), 10-14. https://doi.org/10.9790/5736-0451014

Bybee, R. W., Taylor, J. A., Gardner, A., Van Scotter, P., Powell, J., Westbrook, A., \& Landes, N. (2006). The BSCS 5E instructional model: Origins and effectiveness. Biological Sciences Curriculum Studies.

Che, S. S., Irfan, N. U., Balakrisnan, M., Shakinaz, D., \& Hafizul, F. H. (2015). Aplikasi perisian visualisasi tiga dimensi dalam pembelajaran sains biologi: Implikasi terhadap pelajar berbeza keupayaan spatial [Applications of three -dimensional visualization software in biological science learning: Implications for students of different spatial abilities]. Jurnal Pendidikan Sains \& Matematik Malaysia, 5(1), 57-69.

Cohen, J. (1988). Statistical power analysis for the behavioral sciences (2nd Ed.). Erlbaum.

Craig, P. A., Michel, L. V., \& Bateman, R. C. (2013). A survey of educational uses of molecular visualization freeware. Biochemistry and Molecular Biology Education, 41(3), 193-205. https://doi.org/10.1002/bmb.20693

Dayang Suryati, A. I., \& Mat Rashid, A. (2015). Pengaruh pencapaian akademik dan tahap memori visual jangka pendek terhadap tahap kemahiran visualisasi murid yang mengambil mata pelajaran Lukisan Kejuruteraan [The influence of academic achievement and short -term visual memory level on the level of visualization skills of students taking the subject of Engineering Drawing]. International Journal of Education and Training, 1(2), 1-8.

Fatemah, A., Rasool, S., \& Habib, U. (2020). Interactive 3D visualization of chemical structure diagrams embedded in text to aid spatial learning process of students. Journal of Chemical Education, 97(4), 992-1000. https://doi.org/10.1021/acs.jchemed.9b00690

Ferreira, J. C., \& Patino, C. M. (2016). Randomization: Beyond tossing a coin. Jornal Brasileiro de Pneumologia, $42(5), 310$. https://doi.org/10.1590/S1806-37562016000000296

Gold, A. U., Pendergast, P. M., Ormand, C. J., Budd, D. A., \& Mueller, K. J. (2018). Improving spatial thinking skills among undergraduate geology students through short online training exercises. International Journal of Science Education, 40(18), 2205-2225. https://doi.org/10.1080/09500693.2018.1525621

Hong, D., \& Woo, W. (2006). A framework for virtual reality with tangible augmented reality based user interface. IEICE Transactions on Information and Systems, E89-D(1), 45-52. https://doi.org/10.1093/ietisy/e89-d.1.45

Hoyek, N., Collet, C., Di Rienzo, F., De Almeida, M., \& Guillot, A. (2014). Effectiveness of three-dimensional digital animation in teaching human anatomy in an authentic classroom context. Anatomical Sciences Education, 7(6), 430-437. https://doi.org/10.1002/ase.1446

Ibrahim, D. A., Othman, A., \& Talib, O. (2015). Pengajaran dan pembelajaran kimia organik berdasarkan taksonomi Bloom [Teaching and learning organic chemistry based on Bloom's taxonomy]. Jurnal Pendidikan Bitara UPSI, 9, 12-21.

Johari, S., \& Yusof, A. (2002). Kesukaran menguasai aras mikroskopik dalam pembinaan konsep sains pelajar [Difficulty mastering the microscopic level in the construction of students 'science concepts]. Buletin Kimia Universiti Teknologi Malaysia, 31-40.

Johnstone, A. H. (1993). The development of chemistry teaching: A changing response to changing demand. Journal of Chemical Education, 70(9), 701-705. https://doi.org/10.1021/ed070p701

Karacop, A., \& Doymus, K. (2013). Effects of jigsaw cooperative learning and animation techniques on students' understanding of chemical bonding and their conceptions of the particulate nature of matter. Journal of Science Education and Technology, 22(2), 186-203. https://doi.org/10.1007/s10956-012-9385-9

Keehner, M. (2011). Spatial cognition through the keyhole: How studying a real-world domain can inform basic science-and vice versa. Topics in Cognitive Science, 3(4), 632-647. https://doi.org/10.1111/j.1756-8765.2011.01154.x

Korakakis, G., Pavlatou, E. A., Palyvos, J. A., \& Spyrellis, N. (2009). 3D visualization types in multimedia applications for science learning: A case study for 8th grade students in Greece. Computers \& Education, 52(2), 390-401. https://doi.org/10.1016/j.compedu.2008.09.011

Koyanagi, K., Fujii, Y., \& Furusho, J. (2005). Development of VR-STEF system with force display glove system. In Proceedings of the 15th international conference on Artificial Reality and Telexistence (ICAT2005), (pp. 91-97). Association for Computing Machinery, Christchurch, New Zealand. https://doi.org/10.1145/1152399.1152417

Krejcie, R. V., \& Morgan, D. W. (1970). Determining sample size for research activities. Educational and Psychological Measurement, 30(3), 607-610. https://doi.org/10.1177/001316447003000308

Lohman, D. (1979). Spatial Ability: A Review and Reanalysis of the Correlational Literature. Technical Report No. 8, Aptitiude Research Project. Stanford University, Palo Alto CA.

Louca, L. T., \& Zachari, Z. C. (2012). Modeling-based learning in science education: cognitive, metacognitive, social, material and epistemological contributions. Educational Review, 64(4), 471-492. https://doi.org/10.1080/00131911.2011.628748

Lowe, K. (2004). Interrogation of a dynamic visualization during learning. Learning and Instruction, 14(3), 257-274. https://doi.org/10.1016/j.learninstruc.2004.06.003

Martin, W. E., \& Bridgmon, K. D. (2012). Quantitative and statistical research methods - from hypothesis to results (Research methods for the social sciences 42 ). Wiley.

Mayer, R. E. (2009). Multimedia learning (2nd Ed.). Cambridge University Press. 
McCollum, B., Regier, L., Leong, J., Simpson, S., \& Sterner, S. (2014). The effects of using touch-screen devices on students' molecular visualization and representational competence skills. Journal of Chemistry Education, 91(11), 1810-1817. https://doi.org/10.1021/ed400674v

Mohamed-Salah, B., \& Alain, D. (2016). To what degree does handling concrete molecular models promote the ability to translate and coordinate between 2D and 3D molecular structure representations? A case study with Algerian students. Chemistry Education Research and Practice, 17, 862. https://doi.org/10.1039/C5RP00180C

Moore, K. M. (2017). Effects of spatial ability and three-dimensional interactive computer-assisted instruction on functional anatomy (Doctoral thesis). Faculty of Science and Mathematics Education, Florida Institute of Technology, USA.

Murray, J. K. (2016). An analysis of first-year engineering majors' spatial skill. 2016 ASEE Annual Conference \& Exposition. American Society for Engineering Education-ASEE. https://doi.org/10.18260/p.26562

Narasimha Swamy, K. L., Chavan, P. S., \& Murthy, S. (2018). StereoChem: Augmented reality 3D molecular model visualization app for teaching and learning stereochemistry. IEEE 18th International Conference on Advanced Learning Technologies (ICALT), pp. 252-256. https://doi.org/10.1109/ICALT.2018.00065

Nechypurenko, P. P., Starova, T. V., Selivanova, T. V., Tomilina, A. O., \& Uchitel, A. D. (2018). Use of augmented reality in chemistry education. In A. E. Kiv, \& V. N. Soloviev (Eds.), 1st International Workshop on Augmented Reality in Education (AREdu 2018) (pp. 15-23). CEUR-WS. http://ceur-ws.org/Vol-2257/paper02.pdf

Noraini, I. (2015). Penyelidikan dalam Pendidikan [Research in education]. McGraw Hill.

Okorie, E. U., Agah, J. J., Orakwe, C. U., \& Oyiga, F. K. (2019). Effect of examination and teaching curriculum-based scheme of work on secondary school students' interest and achievement in chemistry. Journal of CUDIMAC (J-CUDIMAC), 6(1), 99109.

Okoye, F. N. (2016). Effects of cooperative and competitive instructional techniques on students' achievement and interest in geometry in Aguata education zone in Anambra State (Unpublished master's degree). Department of Science Education, University of Nigeria, Nsukka.

Olimpo, J. T., Kumi, B. C., Wroblewski, R., \& Dixon, B. L. (2015). Examining the relationship between 2D diagrammatic conventions and students' success on representational translation tasks in organic chemistry. Chemistry Education Research and Practice, 16, 143-153. https://doi.org/10.1039/C4RP00169A

Oliver-Hoyo, M., \& Babilonia-Rosa, M. (2017). Promotion of spatial skills in chemistry and biochemistry education at the college level. Journal of Chemistry Education, 94(8), 996-1006. https://doi.org/10.1021/acs.jchemed.7b00094

Palmer, D., Stough, L., Burdenski, T, Jr., \& Gonzales, M. (2005). Identifying teacher expertise: An examination of researchers' decision making. Educational Psychologist, 40, 13-25. https://doi.org/10.1207/s15326985ep4001_2

Päßler, K., \& Hell, B. (2012). Do interests and cognitive abilities help explain college major choice equally well for women and men? Journal of Career Assessment, 20(4), 479-496. https://doi.org/10.1177/1069072712450009

Pérez, J. R. B., Pérez, M. E. B., Calatayud, M. L., \& Sabater, J. V. (2017). Student's misconceptions on chemical bonding: A comparative study between high school and first year university students. Asian Journal of Education and e-Learning, 5(1), $1-15$.

Piaget, J. (1954). The construction of reality in the child. Basic Books. https://doi.org/10.1037/11168-000

Rayan, B., \& Rayan, A. (2017). Avogadro program for chemistry education: To what extent can molecular visualization and threedimensional simulations enhance meaningful chemistry learning? World Journal of Chemical Education, 5(4), 136-141. https://doi.org/10.12691/wjce-5-4-4

Rose Khairunnisa, R., \& Azlina, A. (2017). 3D spatial visualisation skills training application for school students using hologram pyramid. International Journal on Informatics Visualization, 1(4), 170-174. https://doi.org/10.30630/joiv.1.4.61

Safadel, P., \& White, D. (2020). Effectiveness of computer-generated virtual reality (VR) in learning and teaching environments with spatial frameworks. Applied Sciences, 10(16), 1-17. https://doi.org/10.3390/app10165438

Smith, D., \& Hardaker, G. (2000). e-Learning innovation through the implementation of an Internet supported learning environment. Journal of Educational Technology \& Society, 3, 1-16. https://www.jstor.org/stable/jeductechsoci.3.3.422

Sung, Y., Chang, K., \& Liu, T. (2016). The effects of integrating mobile devices with teaching and learning on students' learning performance: A meta-analysis and research synthesis. Computers $\mathcal{E}$ Education, 94, 252-275, https://doi.org/10.1016/j.compedu.2015.11.008

Taber, K. S. (2005). Learning quanta: Barriers to stimulating transitions in student understanding of orbital ideas. Science Education, 89(1), 94-116. https://doi.org/10.1002/sce.20038

Ulrich, S. (1991). Interest, learning and motivation. Educational Psychology, 26(3\&4), $299-323$. https://doi.org/10.1080/00461520.1991.9653136

Urso, P., \& Fisher, L. (2015). Education technology to service a new population of eLearners. International Journal of Childbirth Education, 30(3), 33-36.

Uttal, D. H., \& Cohen, C. A. (2012). Chapter Four - Spatial thinking and STEM education: When, why, and how? In B. H. Ross (Ed.), The psychology of learning and motivation (vol. 57, pp. 147-181). Elsevier Academic Press. https://doi.org/10.1016/B9780-12-394293-7.00004-2 
Wu, H. K., \& Shah, P. (2004). Exploring visuospatial thinking in chemistry learning. Research in Science Education, 88(3), 465-492. https://doi.org/10.1002/sce.10126

Yang, E. M., Andre, T., \& Greenbowe, T. J. (2003). Spatial ability and the impact of visualization and animation on learning electrochemistry. International Journal of Science Education, 25(3), 329-349. https://doi.org/10.1080/09500690210126784

Yoon, S. Y. (2001). Psychometric properties of the Revised Purdue Spatial Visualization Tests: Visualization of rotations (The Revised PSVT:R). ProQuest LLC. 